Communications in Physics, Vol.21, No. 4 (2011), pp. 333-339

\title{
SYNTHESIS OF GOLD NANOPARTICLES CONJUGATED WITH PROTEIN A: TOWARDS THE APPLICATION IN BIOSENSORS FOR VIRUS DETECTION
}

\author{
TRAN QUANG HUY \\ National Institute of Hygiene and Epidemiology \\ MAI ANH TUAN \\ International Training Institute for Materials Science, \\ Hanoi University of Science and Technology
}

\begin{abstract}
In this article, a facile and effective technique is described to prepare a complex of gold nanoparticles (GNPs)/protein A (PrA) for biosensors in virus detection. GNPs were synthesized by the reduction of tetrachloroauric (III) acid trihydrate using sodium ascorbate, and then coated with $\operatorname{PrA}$ via ultracentrifugation. The complex of GNPs/PrA was characterized using UV-vis spectroscopy and transmission electron microscopy. The immunogold labeling method of scanning electron microscopy was also used to verify the capacity for the detection and binding of GNPs/PrA to $H_{1} N_{1}$ influenza $A$ virus particles. The results showed that GNPs were spherical, uniform shape, and approximately $10 \mathrm{~nm}$ in size. Noticeably, the complex of GNPs/PrA could detect and bind effectively to $H_{1} N_{1}$ influenza $A$ virus particles by a large number of GNPs surrounded. The advantage of the complex of GNPs/PrA showed a highly potential application in biosensors with the improvement of the sensitivity and transducing signal for virus detection.
\end{abstract}

\section{INTRODUCTION}

Gold nanoparticles (GNPs) have been known to have unique and superior properties due to high surface-to-volume ratio, high surface energy, high biocompatibility and ability to facilitate electron transfer between redox proteins and electrode surfaces $[5,9]$. GNPs and their products have been widely used in many fields of life sciences such as immuno-cytochemistry, pathogen detection and biosensors $[7,10,13,15,18]$. It has been shown that the optical and electrical properties of GNPs strongly depend on their size, shape and nanostructure, therefore the controllable synthesis of GNPs with well-defined geometry and properties is a key challenge to promote their applications [11]. Recent development of nanotechnology showed a number of methods to synthesize GNPs, called "top-down" and "bottom-up" resulted in desired nanostructure, size, and shape [5, 9,14]. In these methods, the reduction of gold salts has more interest thanks to ease, low cost and uniform shape of GNPs formed, it is also easy to protect these nanoparticles from aggregation when using some stabilizing agents such as surfactants, polymers, micelles and biomolecules [5]. In biomedical appplications, GNPs usually use bio-molecules for protection and functionalization [6] such as protein A, because this molecule has a high affinity to GNPs. Protein A also bind and orientate well some antibodies immobilized on the solid surfaces $[2,8]$. 
Recently, there has been an increasing demand for the development of biosensors in rapid and label free detection of pathogens [16]. It revealed that the reliability of antibody based-biosensors strongly depends on both the number of antibody immobilized on the sensor surface and the design structure of transducers. Several methods were developed to improve the sensitive and selective performance of biosensors such as minimized electrodes with micro- or nano sizes; and/or the optimal immobilization of antibody on the sensor surface; and/or the modification of sensor surface with nanomaterials (GNPs, silver nanoparticles, carbon nanotubes, etc) $[3,11,13,20,21]$. Despite all these efforts, the improvement of the sensitivity and selectivity of biosensors has not been comparable to the requirement of the market yet. In fact, a few or large number of viruses depends strongly on different clinical samples, this makes the difficulty of most biosensors in virus detection.

In the present work, we describe a facile synthesis of the complex of GNPs/PrA for the effective detection of virus particles as well as improvement of signal between virus particles and electrodes of biosensors.

\section{EXPERIMENTAL}

\section{Reagents}

Tetrachloroauric (III) acid trihydrate $99.5 \%\left(\mathrm{HAuCl}_{4} * 3 \mathrm{H}_{2} \mathrm{O}\right)$, postasium carbonate $\left(\mathrm{K}_{2} \mathrm{CO}_{3}\right)$, protein $\mathrm{A}(\mathrm{PrA})$, bovine serum albumin (BSA) were purchased from Merck. Sodium ascorbate $\left(\mathrm{C}_{6} \mathrm{H}_{7} \mathrm{NaO}_{6}\right)$ and polyethylene glycol (PEG) were purchased from Sigma. Distilled water used was purified through a Millipore system. All other chemicals were of analytical grade.

The samples of inactivated $\mathrm{H}_{1} \mathrm{~N}_{1}$ influenza $A$ virus and human serum containing antibodies to $\mathrm{H}_{1} \mathrm{~N}_{1}$ influenza $A$ virus were provided by the National Institute of Hygiene and Epidemiology (NIHE) of Vietnam.

\section{Synthesis of GNPs}

$0.5 \mathrm{ml}$ of $1 \% \mathrm{HAuCl}_{4}$ and $0.5 \mathrm{ml}$ of $0.1 \mathrm{M} \mathrm{K} \mathrm{K}_{2} \mathrm{CO}_{3}$ were mixed in $12 \mathrm{ml}$ of distilled water at $4{ }^{\circ} \mathrm{C}$. Then, added quickly $1 \mathrm{ml}$ of $0.7 \% \mathrm{C}_{6} \mathrm{H}_{7} \mathrm{NaO}_{6}$ into the above solution during stirring. The color would become immediately purple-red. Distilled water was then added to the solution till $50 \mathrm{ml}$ of volume and boiled until the color became red. The morphology and size distribution of GNPs were immediately checked by using the transmission electron microscopy (JEM 1010, JEOL) operating at $80 \mathrm{kV}$

\section{Preparation of GNPs/PrA complex}

$1 \mathrm{mg} / \mathrm{ml}$ of PrA was mixed with $15 \mathrm{ml}$ of the GNPs solution. After $5 \mathrm{~min}, 0.15 \mathrm{ml}$ of $0.02 \%$ PEG was added to stabilize the complex. GNPs/PrA solution was ultracentrifuged (Airfuge, Beckman Coulter) for $45 \mathrm{~min}$ at 70,000 rpm. The supernatant was removed carefully. The pellet was dissolved in the remained solution and layered over a $50 \%$ glycerol gradient containing $0.15 \mathrm{M} \mathrm{NaCl}, 0.01 \mathrm{M}$ sodium phosphate, $\mathrm{pH} 7.4$, and $0.02 \%$ sodium azide. The gradient was centrifuged for $20 \mathrm{~min}$ at 20,000 rpm. A solution of GNPs/PrA complex was obtained by collecting the red zone of the gradient. The final product of GNPs/PrA was investigated using the UV-vis spectrometry (HP 8453 Spectrophotometer) 
in the wavelength region $300-900 \mathrm{~nm}$ and transmission electron microscopy (JEM 1010, JEOL) operating at $80 \mathrm{kV}$.

\section{Immuno-gold labeling test}

Firstly, $\mathrm{H}_{1} \mathrm{~N}_{1}$ influenza $\mathrm{A}$ virus was inactivated and fixed in $2.5 \%$ glutaraldehyde for $1 \mathrm{hr}$ at $4^{\circ} \mathrm{C}$. After that, dehydration by series of alcohol concentration and a droplet of virus sample was place on the aluminum surface, treated with $2 \%$ BSA/PBS for 20 min to block non-specific antigenic sites. The sample was then incubated with the diluted human serum in $0.5 \% \mathrm{BSA} / \mathrm{PBS}$ for $45 \mathrm{~min}$. After careful washes with $0.2 \% \mathrm{BSA} / \mathrm{PBS}$, the sample was subsequently incubated with the GNPs/PrA complex (diluted 1:60 in 0.5\% BSA/PBS) for 30 min, washed with PBS and air-dried. The sample was coated by a thin platinum $(\mathrm{Pt})$ layer before observation with a high resolution scanning electron microscopy (FESEM- S4800, Hitachi).

\section{RESULTS AND DISCUSSION}

\section{UV-vis spectroscopy analysis}

The GNPs were obtained by the reduction from a gold salt using sodium ascorbate. This process occurred through the electrons transfer from the hydroxyl groups of the sodium ascorbate to the $\mathrm{Au}^{3+}$ ions leading to the formation of $\mathrm{Au}^{0}$. The obtained solution was checked by UV-vis spectrometry. Fig. 1 shows UV-vis absorption spectra of GNPs/PrA complex. The surface plasmon resonance (SPR) peak of GNPs was found at the wavelength of $524 \mathrm{~nm}$, indicated the formation of the GNPs. The absorbance is extremely sensitive to the morphology and nature of GNPs formed, their inter-particle distances and the surrounding media [12]. According to the Mie's theory, the averaged GNPs diameter could be estimated from the maximum absorption band, the diameter of GNPs increased when the maximum absorption band shifts to longer wavelength [4]. It is important to note that the use of $\operatorname{PrA}$ as a stabilizer resulting in the absorption peak of GNPs/PrA complex nearly unchanged even after 6 months in storage at $-20^{\circ} \mathrm{C}$. These results indicated that PrA could also stabilize GNPs as well as protect them from aggregation and precipitation over the time. Moreover, PrA could retain well its biological activity at this temperature [1].

\section{Stability of GNPs size distribution}

The morphology and size distribution of GNPs in the colloidal solution were investigated using transmission electron microscopy. Fig. 2A shows GNPs before treatment with PrA, these GNPs are mainly spherical, but some of GNPs clustered and void spaces made which could lead to the aggregation of GNPs. Fig. 2B shows the distribution histogram of GNPs reduced in which the average size is about $10 \mathrm{~nm}$, this result is also highly agreed with the UV-vis investigation. Furthermore, the image revealed GNPs formed with a complete reduction due to sodium ascorbate, this reductant was also preferred to form GNPs in several studies [19,22].

After treatment with PrA, a mono-dispersed and non-clustered distribution of GNPs was found (Fig. 3A). This can be understood that the use of ultracentrifugation and glycerol gradient resulted in the adhesion of PrA molecules around GNPs, and prevented 


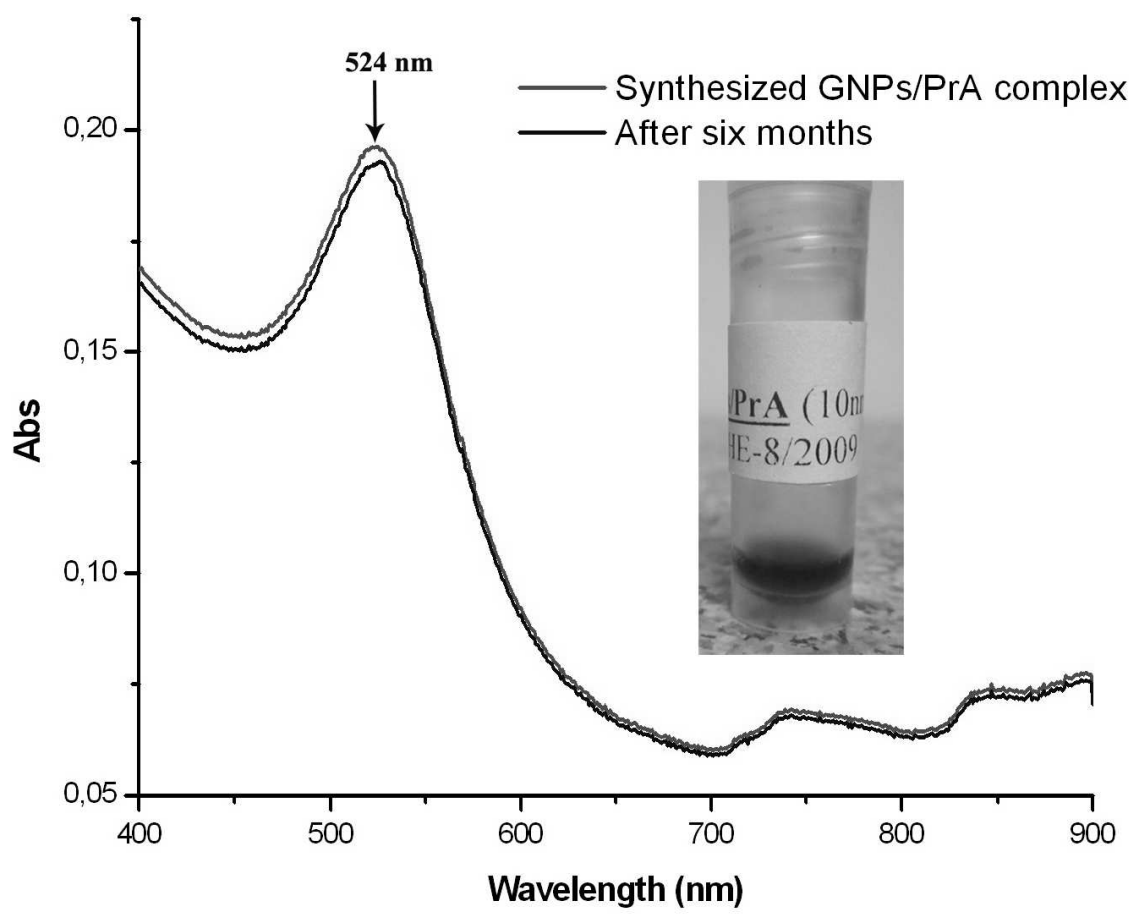

Fig. 1. UV-vis absorption spectra of the complex of GNPs/PrA synthesized, and after six months in storage at $-20^{\circ} \mathrm{C}$. The inset is the colloidal solution of GNPs/PrA synthesized.
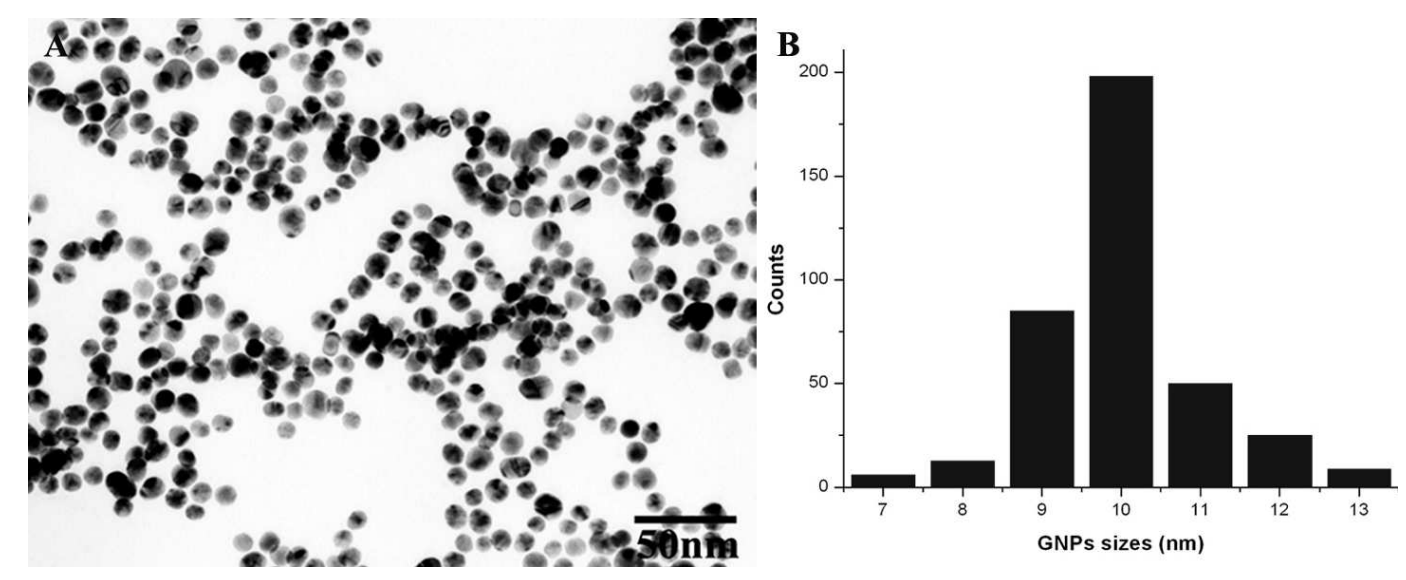

Fig. 2. TEM image of GNPs before treatment with PrA (A), and sizes distribution histogram of 386 GNPs in the colloidal solution (B) 
GNPs from aggregation. The result showed that PrA revealed as a good stabilizer in comparison with other stabilizers such as polymers and micelles [5,9]. GNPs also remained spherically and homogeneously over the time. The complex of GNPs/PrA stabilized for more than six months in storage at $-20^{\circ} \mathrm{C}$ [Fig. 3B]

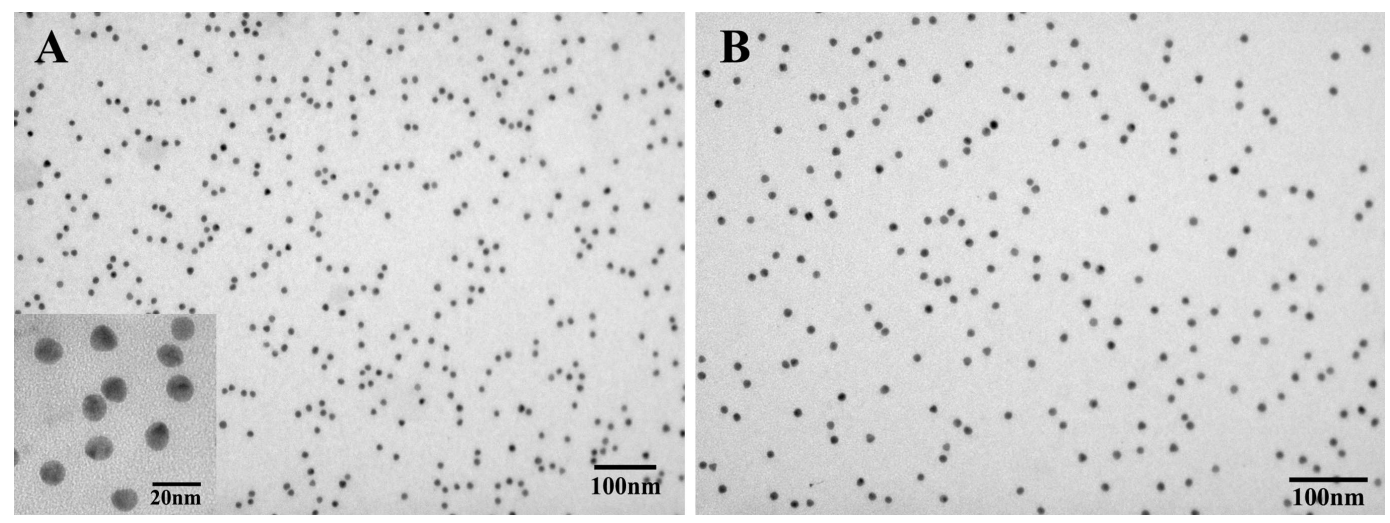

Fig. 3. GNPs after treatment with PrA. (A) The distribution of GNPs and the left corner inset of GNPs of approximately $10 \mathrm{~nm}$ in size. (B) the stability of GNPs/PrA distribution after 6 months in storage at $-20^{\circ} \mathrm{C}$

\section{Immunogold labeling reaction with $\mathbf{H}_{1} \mathbf{N}_{1} A$ influenza virus particles}

In order to estimate the biological activity of the complex of GNPs/PrA synthesized, this product was used for immunogold labeling methods in the detection of $\mathrm{H}_{1} \mathrm{~N}_{1}$ A influenza virus particles by scanning electron microscopy. Fig. 4a shows the image of many $\mathrm{H}_{1} \mathrm{~N}_{1} \mathrm{~A}$ influenza virus particles (arrows) before the immunogold labeling reaction, this image revealed the morphology of $\mathrm{H}_{1} \mathrm{~N}_{1}$ A influenza virus particles with sphericaland rod-like shapes and withour the attachment of GNPs. Whereas after the reaction with GNPs/PrA associated with human serum containing antibodies to $\mathrm{H}_{1} \mathrm{~N}_{1}$ influenza A virus, the results of the Fig. 4b revealed these virus particles localized by many GNPs (head arrows). A large number of GNPs surrounded around $\mathrm{H}_{1} \mathrm{~N}_{1}$ influenza A virus particles demonstrated that many viruses could be detected by the localization of GNPs. In this method, the Fc fragment of the anti-viral IgG antibodies would bind strongly to the PrA, and the Fab fragments bind specifically to the viral antigen sites [1]. It also proved that many anti - viral antibodies could be attached on the surface of GNPs via PrA molecules $[10,15]$.

\section{Towards the application of GNPs/PrA complex in biosensors for virus detec- tion}

GNPs have excellently biocompatible and potential carriers, especially their ability to facilitate the direct transfer of electrons between redox proteins and micro-electrodes leading to the performance of the electrochemical sense even without electron transfer mediators [13]. In a recent review, Yuanyuang et al. showed the extensive application of GNPs in construction of electrochemical biosensors in which GNPs play crucial roles both 


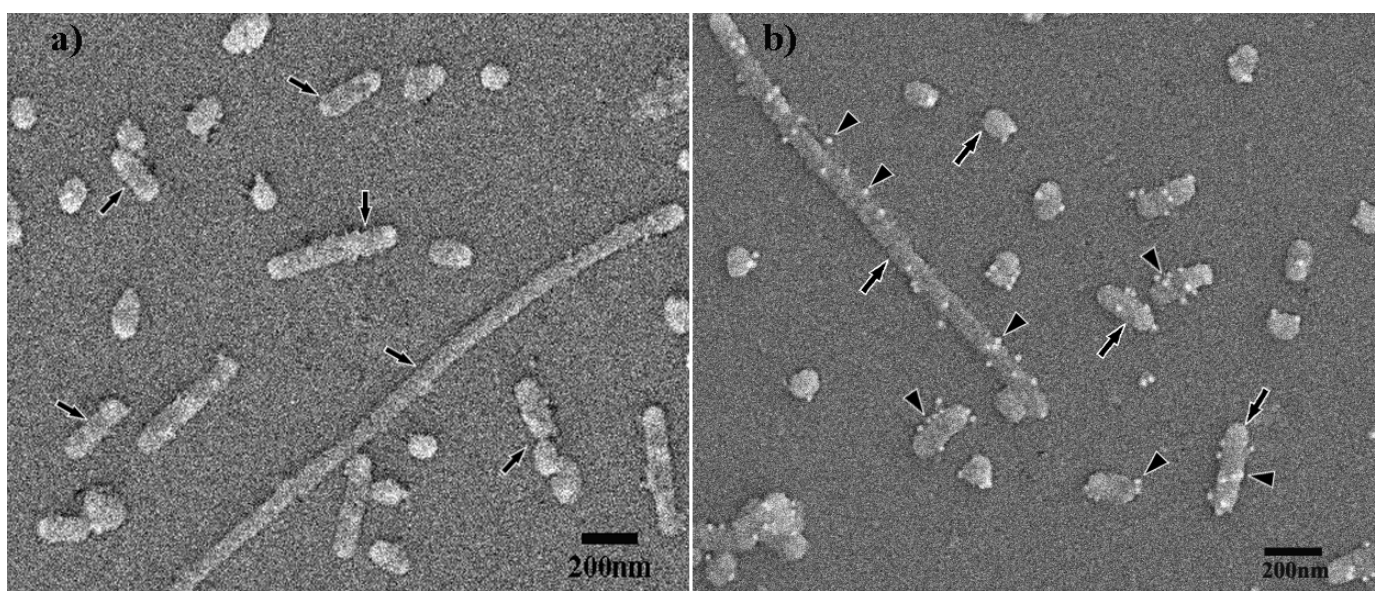

Fig. 4. SEM photograph of H1N1 influenza A virus particles: (a) without the use of GNPs/PrA complex, and (b) with the use of GNPs/PrA complex (arrows: H1N1 influenza A virus particles; arrowheads: GNPs).

in the enhancement of the electrochemical signal biosensing process and their mechanism for improving analytical performance, such as: electron transfer "electron wires", immobilization platform and electrocatalyst [11]. Moreover, $\operatorname{PrA}$ is very heat-stable and retains the native conformation with some physical and chemical factors, it binds specifically to the Fc region of the immunoglobulin molecules without disturbing the binding of antigen [1]. Chih et al. reported that using PrA is a good way of immobilizing antibodies onto the silica based surface [2]. Another paper also reported that 30\%-70\% higher antibodies could be bound on silica-tagged PrA than on uncoated silica surface [8]. In a recent study, we have demonstrated that the use of prA is an advantageous way to immobilize serum antibodies for electrochemical biosensors [20]. In addition, our results of this work also show the comlex of GNPs/PrA could detect and bind well to $\mathrm{H}_{1} \mathrm{~N}_{1} \mathrm{~A}$ influenza virus particles. Hence, the combination of GNPs and PrA is expected to be a good idea for improvement of the sensitivity and transducing signal in biosensors for virus detection.

\section{CONCLUSION}

In this paper, we represented the facile synthesis of GNPs/PrA complex for biosensor applications in virus detection. The results showed that this technique provided GNPs spherically, homogeneously and approximately $10 \mathrm{~nm}$ in size. The use of PrA as the stabilizer resulted in a mono-dispersed and non-clustered distribution of GNPs in solution over the time. Furthermore, the complex of GNPs/PrA formed could detect and bind well to $\mathrm{H}_{1} \mathrm{~N}_{1}$ influenza $A$ virus particles, and it showed the potential applications in the improvement of the sensitivity and transducing signal in biosensors for virus detection.

\section{ACKNOWLEDGEMENTS}

The authors would like to thank MSc. Nguyen Thanh Thuy, National Institute of Hygiene and Epidemiology for the kind support of SEM immunogold labelling tests; 
Dr. Le Anh Tuan, Advanced Intitute for Science and Technology, Hanoi University of Science and Technology for helpful comments. This work was financially supported by Vietnam's National Foundation for Science and Technology Development (NAFOSTED), project code: 106.16.181.09.

\section{REFERENCES}

[1] A. Surolia, D. Pain and M.I. Kahn, Trend. Biochem. Sci. 7 (1982) 74

[2] C. S. Chih, Z.W. Tzong, K.C. Li, H.Y Hui and F.T Dar, Anal. Chim. Acta 479 (2003) 117

[3] D.L. Alfredo, M. Escosura, P. Claudio and M. Arben, Materialstoday 13 (2010) 24

[4] G. Mie. Ann. Phys. (Leipzig) 25 (1908) 377

[5] G. Shaojun and W. Erkang. Anal. Chim. Acta 598 (2007) 181

[6] H. Abdelghani, A. Marya, L. Shiyong and N. Ravin. J. Phys. Chem. C112 (2008) 12282

[7] H.M.E. Azzazy and M.H.M. Mansour, Clin. Chim. Acta 403 (2009) 1

[8] H.Y. Takeshi, N. Ken-ichi, I. Yoshiaki, T. Keigo, A. Satoka, H. Ryuichi, and K. Akio, Anal. Biochem. 385 (2009) 132

[9] J. Zhou, J. Ralston, R. Sedev and D.A. Beattie. J. Colloid Interface Sci. 331 (2009) 251

[10] J.W. Slot, and H.J. Geuze, J. Cell Biol. 90 (1981) 533

[11] L. Yuanyuang, J.S. Hermann and X. Shunquing, Gold Bulletin 10 (2010) 29

[12] M. Audrey and G. Fr \'ed `'e ric, New J. Chem. 30 (2006) 1121

[13] M.P. Jose, Y. Paloma, and G.C. Araceli, Electrochimica Acta 53 (2008) 5848

[14] N.T. H. Lien, L.T. Huyen, V.X. Hoa, C.V. Ha, N.T. Hai, L.Q. Huan, F. Emmanuel, D.Q. Hoa, and T.H. Nhung, Adv. Nat. Sci.: Nanosci. Nanotechnol. 1 (2010) 025009

[15] N.V. Man et al., C. R. Acad. Sci. Paris. Life Sciences 324 (2001) 815

[16] P. Bobby, D.M. Roland, and P. Gordon, Analyst 131 (2006) 1979

[17] P. Setua, A. Chakraborty, D. Seth, M.U. Bhatta, P.V. Satyam and N. Sarkar. J. Phys. Chem. C111 (2007) 3901

[18] S.A. Sarit, R. Subinoy, H.P. Myoung, K.K. Chae, C.Y. Chang and M.R. Vincent, Adv. Drug Deliv. Reviews 62 (2010) 316

[19] S.H. Ding, W.P Qian, Y. Tan, and Y. Wang, Langmuir 22 (2006) 7105

[20] T. Q. Huy, N. T. H. Hanh, P. V. Chung, D. D. Anh, P. T. Nga and M. A. Tuan, Appl. Sci. Surf. 257 (2011) 7090

[21] V. V Jithesh and Y Kaiming, Biotech. Progress 23 (2007) 517

[22] Y. Tan, W. P. Qian, S. H. Ding, and Y. Wang, Chem. Mater. 18 (2006) 3385

Received 5 June 2011. 